\title{
Care of patients with Huntington's disease in South America: a survey
}

\author{
Cuidado de pacientes com doença de Huntington na América do Sul: um inquérito \\ Ricardo Oliveira Horta Maciel1, Francisco Eduardo Costa Cardoso1, Pedro Chaná-Cuevas², Carlos Cosentino², \\ William Fernández ${ }^{4}$, Carlos R. M. Rieder ${ }^{5}$, Marcos Serrano-Dueñas ${ }^{6}$, Roberto Weiser ${ }^{7}$
}

\begin{abstract}
Huntington's disease (HD) is a rare neurodegenerative disease with a multitude of symptoms, which requires access to specialized multidisciplinary care for adequate management. The aim of this study was to survey the characteristics of care in various HD centers in South America (SA). Methods: A questionnaire was sent to 24 centers involved in the care for HD patients in SA. Results: Of the total 24 centers, 19 (79.2\%) are academic units. The majority of centers (62.5\%) are general movement disorders clinics. Multidisciplinary care is available in 19 (79.2\%) centers and in $20(83.3 \%)$ care is provided free of charge. Genetic testing and counseling are available in 25 and $66.6 \%$ of centers, respectively. The majority of centers (83.3\%) have no institutional support for end-stage care. Conclusions: Although HD centers in SA are committed to providing multidisciplinary care, access to genetic counseling and end-stage care are lacking in most centers.
\end{abstract}

Key words: Huntington disease, comprehensive health care, genetic counseling.

\section{RESUMO}

A doença de Huntington $(\mathrm{DH})$ é uma doença neurodegenerativa rara que requer tratamento multidisciplinar especializado para manejo adequado. O objetivo do presente trabalho foi pesquisar as características da assistência à saúde em centros de DH na América do Sul (AS). Métodos: Um questionário foi enviado para 24 centros envolvidos no cuidado de pacientes com DH na AS. Resultados: Dos 24 centros, 19 (79,2\%) são unidades acadêmicas. A maioria (62,5\%) são clínicas de distúrbios dos movimentos. Cuidado multidisciplinar é disponível em 19 (79,2\%) dos centros e em 20 (83,3\%), o tratamento é gratuito. 0 teste e o aconselhamento genético estão disponíveis em 25 e 66,6\% dos centros, respectivamente. Não há suporte institucional para cuidado terminal em 83,3\% dos centros. Conclusões: Apesar dos centros de DH na AS terem compromisso com o provimento de cuidados multidisciplinares, o acesso a aconselhamento genético e a tratamento na fase terminal são falhos na maioria dos centros.

Palavras-Chave: doença de Huntington, assistência integral à saúde, aconselhamento genético.

Huntington's disease (HD) is a rare autosomal dominant neurodegenerative disease characterized by movement disorders, cognitive decline and psychiatric symptoms ${ }^{1}$. No current efficacious treatment exists, and due to its relentless progression, patients face increasing disability due to a combination of motor impairment and cognitive decline, leading to loss of ambulation, dysphagia and dementia. Loss of autonomy becomes a constant feature as the disease progresses and patients frequently require round-the-clock care in the final stages of disease $\mathrm{e}^{2,3}$.

Management of patients with $\mathrm{HD}$ often requires the involvement of diverse health care professionals including

\footnotetext{
Movement Disorders Clinic, Department of Neurology, Universidade Federal de Minas Gerais (UFMG), Belo Horizonte MG, Brazil.

${ }^{1}$ Movement Disorders Clinic, Department of Neurology, UFMG, Belo Horizonte MG, Brazil;

${ }^{2}$ Centro de Trastornos del Movimiento (CETRAM), Facultad de Ciencias Médicas, Universidad de Santiago de Chile, Santiago, Chile;

${ }^{3}$ Movement Disorders Unit, Instituto Nacional de Ciencias Neurológicas, Lima, Peru;

«Universidad Nacional de Colombia, Institute of Genetics, Bogotá, Colombia;

5Universidade Federal Ciências da Saúde Porto Alegre (UFCSPA), Porto Alegre RS, Brazil;

${ }^{6}$ Movement Disorder and Biostatistics Units, Neurological Service, Carlos Andrade Marín Hospital and Medicine Faculty, Pontifical Universidad Católica del Ecuador, Quito, Ecuador;

7Department of Neurology, Instituto de Clínicas, Tamanaco, Caracas, Venezuela.

Correspondence: Francisco Cardoso; Avenida Pasteur 89 / 1.107; 30150-290 Belo Horizonte MG - Brasil; E-mail: cardosofe@terra.com.br

Conflict of interest: Francisco Cardoso is Secretary-Elect of the Movement Disorders Society; Brazilian Academy of Neurology Delegate to WFN; Vice-President of the Latin American Huntington Disease Network; honoraria from Roche and Moksha8. Pedro Chana-Cuevas has been a participant in the speaker's bureaus of UCB Pharma, Ipsen, GSK, and Boehringer-Ingelheim. Carlos Rieder is Member of the Education Committee of the Movement Disorders Society/Pan American Section; honoraria from Roche, Boehringer Ingelheim, Moksha8. Carlos Cosentino is President of the Peruvian Neurological Society.

Reiceved 12 December 2012; Received in final form 17 December 2012; Accepted 27 December 2012.
} 
nurses, physiotherapists, speech therapists, psychologists, occupational therapists, and genetic counselors, who have important roles in improving the quality of life and managing the disabilities of HD patients ${ }^{4}$. Moreover, in the latter stages of disease, nursing home facilities and end-stage palliative care are often required, as caregiver burden and quality of life become major concerns ${ }^{5}$.

The availability and quality of care for patients with HD living in South America (SA) has not been reported in the literature. The purpose of this study was to survey the characteristics of care provided in various centers involved in the management of HD patients throughout SA.

\section{METHODS}

Questionnaires were sent to 24 centers involved in the care of HD patients in various countries of SA with reputable expertise in the field and active participation in regional Movement Disorders forums. This survey included questions on the clinics' profile and institutional status, staff composition, clinical scales used for patient evaluation, access to neuroimaging, genetic testing and counseling, and end-stage care support.

\section{RESULTS}

Of the 24 centers evaluated, 14 were located in Brazil, 4 in Argentina, 2 in Chile and 1 in Colombia, Ecuador, Peru, and Venezuela, each. The combined population of the cities where the centers are located is of 80 million people, comprising $20.7 \%$ of the total population of SA or $21.7 \%$ of the population of their respective countries.

\section{Profile of centers}

The majority of centers, $19(79.2 \%)$, are affiliated with an academic institution, and all are specialized clinics, either of general movement disorders (15/24 or $62.5 \%)$, HD-only clinics $(6 / 24$ or $25 \%)$ or neurogenetics clinics (3/24 or $12.5 \%)$. Most clinics are open once a week $(22 / 24$ or $91.6 \%)$ one $(4.2 \%)$ is open twice a week, and another (4.2\%) five times a week.

Multidisciplinary care is available in 19 of the 24 (79.2\%) centers; composition of the teams is summarized in Table 1. Most centers (20/24 or $83.3 \%$ ) provide care free of charge to patients.

\section{Patient assessment}

Clinical assessment protocols adopted and neuroimaging tests available in the various centers are reported in Table 2. Genetic testing is available in 6 clinics (25\%) and in other $14(58.3 \%)$ it is available elsewhere.

\section{End-stage care}

Most centers (20/2 or $83.3 \%$ ) have no institutional support for end-stage care. In other $2(8.3 \%)$ it is accessible via a public institution, or covered by health insurance in other $2(8.3 \%)$ centers.

\section{DISCUSSION}

Patients with HD and other neurodegenerative diseases often require coordinated multidisciplinary care to cater for different needs during the course of disease. Different levels of care are required as the disease progresses, from symptomatic therapy, psychological support to patients and caregivers, to genetic counseling to family members and, ultimately, to palliative care $\mathrm{c}^{6-8}$.

This study shows that centers responsible for managing patients with HD throughout SA are committed to providing, mostly in free-of-cost settings, the best level of care possible, as attested by the fact that most institutions have multidisciplinary teams capable of tailoring treatment strategies to individual patient needs.

Table 1. Health care professionals composition of Huntington's disease clinics.

\begin{tabular}{lcc} 
Health profession & $\begin{array}{c}\text { Absolute } \\
\text { frequency }\end{array}$ & $\begin{array}{c}\text { Relative } \\
\text { frequency (\%) }\end{array}$ \\
\hline Neurologists & 24 & 100 \\
Physiotherapists & 13 & 54.2 \\
Geneticists & 12 & 50 \\
Speech therapists & 11 & 45.8 \\
Nurses & 10 & 41.6 \\
Psychologists & 10 & 41.6 \\
Occupational therapists & 7 & 29.2 \\
Dentists & 6 & 25 \\
Psychiatrists & 4 & 16.6 \\
\hline
\end{tabular}

Table 2. Clinical assessment tools and diagnostic neuroimaging used in Huntington's disease centers.

\begin{tabular}{lcc} 
& $\begin{array}{c}\text { Absolute } \\
\text { frequency }\end{array}$ & $\begin{array}{c}\text { Relative } \\
\text { frequency (\%) }\end{array}$ \\
\hline Rating Scales & 15 & 62.5 \\
MMSE & 13 & 54.4 \\
UHDRS & 2 & 8.3 \\
FAB & 2 & 8.3 \\
MoCA & & \\
Neuroimaging & 19 & 79.2 \\
CT Scan & 16 & 66.6 \\
MRI & 5 & 20.8 \\
SPECT & 1 & 4.2 \\
PET & & \\
\hline
\end{tabular}

MMSE: mini-mental state examination, UHDRS: Unified Huntington Disease Rating Scale; FAB: Frontal Assessment Battery, MoCA: Montreal Cognitive Assessment;CT Scan: computed tomography scan;MRI: magnetic resonance image; SPECT: single photon emission computed tomography; PET: positron emission tomography. 
However, a number of weaknesses in this current model need to be addressed. First, the number of centers capable of caring for HD patients is insufficient to cover to the demand in the various countries in relation to the estimated prevalence of the disease in SA. Additionally, few centers have psychiatrists and geneticists in staff to address major patient and caregiver concerns ${ }^{5}$ regarding psychiatric and genetic counseling. Genetic testing is available only in a minority of centers, and most patients have to resort to externally provided testing, which can often be expensive, far from their hometowns, and performed without adherence to international recommendations. Finally, the inexistence of structured end-stage disease care and institutionalized support are major obstacles to proper care ${ }^{9,10}$. This needs to be improved as the burden of care can become overwhelming in the final stages of disease, especially in families with multiple persons affected and/or in poor socioeconomic settings.

One limitation of this study is the disproportionate amount of Brazilian centers evaluated in relation to other countries of SA. Although we have made an effort to reach out for as many centers specializing in the care of HD patients as possible, units that may exist in other areas were not included in this study. Even if this is the case, it is fair to conclude that half of the population of SA, perhaps even more in some areas of the continent, cannot access centers capable of delivering specialized care for HD patients.

The European HD Network (EHDN) is a multicenter, multi-national initiative to facilitate HD care and research throughout Europe, including, but not limited to, management of large observational studies, interventional trials, and working groups focused on developing evidence-based guidelines for best-practice standards of care in HD. The creation of the EHDN, has contributed to achieving the goals of multidisciplinary, patient-centered and individualized care as the standards of care for HD patients in Europe, as patients tend to rely on the availability of primary or community care services for adequate management of their condition ${ }^{11}$. The institution of the Latin American HD Network in the models of the EHDN will hopefully aid in improving treatment for SA patients in a similar manner.

\section{ACKNOWLEDGEMENT}

We thank Katherine Bazley RN for her secretarial assistance.

\section{References}

1. Walker FO. Huntington's disease. Lancet 2007;369:218-228.

2. Rosenblatt A, Kumar BV, Margolis RL, Welsh CS, Ross CA. Factors contributing to institutionalization in patients with Huntington's disease. Mov Disord 2011;26:1711-1716.

3. Travers E, Jones K, Nichol J. Palliative care provision in Huntington's disease. Int J Palliat Nurs 2007;13:125-130.

4. Phillips W, Shannon KM, Barker RA. The current clinical management of Huntington's disease. Mov Disord 2008;23:1491-1504.

5. Skirton H, Williams JK, Jackson Barnette J, Paulsen JS. Huntington disease: families' experiences of healthcare services. J Advanc Nurs 2010;66:500-510.

6. Soltysiak B, Gardiner P, Skirton H. Exploring supportive care for individuals affected by Huntington disease and their family caregivers in a community setting. J Clin Nurs 2008;17:226-234.
7. Skirton $\mathrm{H}$, Glendinning N. Using research to develop care for patients with Huntington's disease. Brit J Nurs 1997;23:83-90.

8. Etchegary H. Healthcare experiences of families affected by Huntington disease: need for improved care. Chronic IIln 2011;7:225-238.

9. Dellefield ME, Ferrini R. Promoting excellence in end-of-life care: lessons learned from a cohort of nursing home residents with advanced Huntington disease. J Neurosci Nurs 2011;43:186-192.

10. Veenhuizen RB, Kootstra B, VinkW, et al. Coordinated multidisciplinary care for ambulatory Huntington's disease patients. Evaluation of 18 months of implementation. Orphanet J Rare Dis 2011;6:77.

11. Busse M, Al-Madfai H, Kenkre J, Landwehrmeyer GB, Bentivoglio A, Rosser A. Utilisation of healthcare and associated services in Huntington's disease: a data mining study. PLoS Curr Huntington Dis 2011;3:RRN1206. 